\title{
The Challenges of Translating Idioms from Arabic into English A Closer look at Al Imam AL Mahdi University - Sudan
}

\author{
Amin Ali Al Mubarak \\ English language Department, Al Imam AL Mahdi University, Sudan
}

Received: 20-11-2016

doi:10.7575/aiac.ijclts.v.5n.1p.53
Accepted: 18-01-2017

Published: 31-01-2017

URL: http://dx.doi.org/10.7575/aiac.ijclts.v.5n.1p.53

\begin{abstract}
This particular study explores and identifies the obstacles faced in the process of translating idioms from the Arabic into the English. In fact, one of the most challenging issues in the field of translation is the process of translating idioms from the source language into the target language with maximum success in conveying similar connotation, conceptualization, as well as shades of meaning. Therefore, in meeting the objectives outlined in this study, a purposive sample that consisted of forty students pursuing B.A. in English at the Arts College of Al Imam AL Mahdi - Sudan had been selected. Other than that, the researcher employed the descriptive approach in the study to identify and to list down the problems faced by students in applying certain strategies to translate idioms from Arabic into English. As such, a translation test was carried out as an instrument for data collection. The test was comprised of twelve Arabic proverbs based on Speake (2008) classification of Proverbs, i.e. everyday experience, traditional wisdom, and folklore, to name a few. As a result, the outcomes of the study revealed several issues that must be ironed out in order to translate idiomatic expressions appropriately and accurately. Some significant factors that had been included are cultural aspects, sociolinguistic elements, linguistic and stylistic considerations and some particular meta-lingual factors.
\end{abstract}

Keywords: Translation Strategies, Idioms, Sociolinguistic Elements, Meta-Lingual Factors

\section{Introduction}

Language functions as an apparatus or a link that strengthens the relationships between nations so as to coordinate, as well as to tackle the difficulties faced by humans, in general, and to mirror our philosophies and convictions, in precise. As such, idioms and fixed expressions have been accepted as a natural aspect of every language that plays a rather significant function. Moreover, since the importance of these collocations cannot be undermined or go astray from the superficial meaning of the words that constitute them, a number of issues have been determined in both processes of comprehending and translating them. The process of translating idioms and fixed expressions from source language into target language is indeed a fine work, in which a translator must possess a decent amount of knowledge in both languages and cultures, besides being capable of distinguishing and coping with unexpected concerns while fine tuning the most accurate and identical inter-lingual idiomatic pairs. Additionally, those who are multilingual have the opportunity to utilize wholesome unique expressions to express a comparative significance in an effective manner that is intelligible by the others including those with knowledge of another language, or otherwise it may turn to be a complete gibberish or even worse, a cause for misunderstanding that could have been easily avoided. This originates from the fact that every language has some cultural influences, which make it stand out and may project some dissimilarity when translated into a different language. Furthermore, the effects of a few contrasts, such as geographical locations, religion, different ideologies, as well as social classes of languages and societies, determine the approaches of comprehending and translating idiomatic expressions from one language into another. Therefore, this study looks into the strategies that can be applied for translation of idioms, which derive as outcomes from earlier researches in this field.

\section{The Problem Statement}

Despite of the late advancement in the field of translation theory, some essential questions have been raised concerning the methods of translating idioms from Arabic into English, the challenges faced during the translation process, as well as the solution to overcome the glaring issues. Hence, applying distinctive translation strategies is one of the apparatuses that translators have utilized to address difficulties faced in translation. Besides, idioms are indeed associated to translation issues, particularly when translation takes place between two different languages, like Arabic and English, which are substantially varied linguistically and culturally. In some cases, idioms are treated as figures of speech, as defined in the Collins English Dictionary (2006) as an expression, for instance, a simile does not have any straight meaning, yet arranged as multi-word expressions as the content functions as units. In addition, idioms should not be separated by their components, but read as fixed expression Cowie and Mackin (1975). Thus, this research lists the obstacles faced by students while translating idioms from Arabic language into English language. This is closely related to the phenomenon of deciphering idioms, which is viewed as a challenging task among students from $\mathrm{Al}$ Imam AL Mahdi University - Sudan because the meaning of idioms cannot be separated from the implications of their components In addition, Baker (2011) pointed out that idioms are "frozen examples of language that allow little or no 
variety in form and regularly convey implications that cannot be deduced from their individual parts". Other than that, Gottlieb (1997) asserted that idioms cannot be straightforwardly translated by one who just understands the general meaning of the related constituents. Furthermore, Adelnia and Dastjerdi (2011) claimed that, an idiom is an expression made out of no less than two lexical items, with a meaning that is difficult to derive literally and which functions semantically as one unit. Besides, Arabic and English languages are both rich in idioms. Nevertheless, some lexical gaps do exist between the two languages, thus making translating idioms a challenge among students, along with the various strategies used to overcome the glitches.

\section{Research Questions}

1. What are the obstacles of translation strategy encountered by students in translating idioms from Arabic language into English language?

2. How do the students deal with different translation strategies in translating idioms from Arabic language into English language?

\section{Research Objectives}

1. To, explore the obstacles of translation strategy encountered by the students in translating idioms Arabic language into English language.

2. To, help the students to deal with different translation strategies in translating idioms from Arabic language into English language.

\section{Significance of the Study}

This study was spurred by the way the students confronted with difficulties in comprehending idioms, which becomes even trickier when they are required to comprehend these expressions and translate them into English. Hence, the outcomes of the study are expected to be rise:

1. Students' attention to the hazardous areas that they may confront, as well as to expose them to the diverse strategies that can be applied when managing idioms in translation.

2. Awareness among novice translators and, instructors of the types of problems faced when deciphering idioms. This knowledge may assist instructors in developing strategies to train students on how translate idioms in a more accurate manner.

Hence, from the theoretical point of view, this study should be able to reveal some light on the reasons why students face challenges with idioms in both cognizance and translation. This can be accomplished by pointing out the reasons behind the mistakes conferred by the subjects, as well as the translation methods adopted.

\section{Methodology}

The research procedure and methods adopted in this research were selected especially to achieve the research objectives. Besides, the rationale is deliberated and explained in terms of sample selection, test procedures, interview procedures, instrument, data collection, and data analysis.

\subsection{Sample}

The sample selected for this research involves the students from the Arts College at Al Imam AL Mahdi University Sudan. In precise, several rationales have been figured out to specifically select this particular group of learners as participants. First, they must be pursuing towards the end of their program course, and second, they must be native speakers of the Arabic language. Therefore, a total of forty students aged between 20 and 22 years old were selected as the participants of the study. Moreover, as all the participants were in their fourth year, these students had been expected to have a good command of the English language and do not have any substantial linguistic problems when translating from Arabic to English. For those reasons, the final year students had been opted as the most appropriate participants for this research.

\subsection{Test Procedures}

As the aim of this research is to determine the problems faced by students in translating idioms from Arabic to English, a test was designed that included a reasonable number of questions (i.e., 12 items) with simple structures. The test was carried out to all students at the hall. Before the test began, a short briefing on the nature of the study, as well as the objectives of the test, was given. This briefing assisted them in comprehending the significance of the test. Moreover, it was believed that by explaining the idea behind the test, the students would realize that the test was not part of their course work and their grades would be unaffected, but merely for research purpose. In addition, the respondents were also informed that all the answers provided would remain confidential.

\subsection{Interview}

Personal interviews were conducted with the respondents. As for this study, the interview was employed as a data collection method. The interview was carried out to further probe into the problems faced when translating idioms from Arabic to English. All answers provided by the respondents during the interview were tape-recorded. Besides, 20 respondents were selected for the interview based on the suggestion that a sample size between 12 and 60 is sufficient (Hawkins et al., 1987). The following questions were posed during the interview session:

1. What are the main difficulties that you have faced as a student of translation in translating idiomatic expressions? 
2. What cause the challenges for translating idiomatic expressions?

3. What solutions can you propose to overcome the challenges faced in translating idiomatic expressions?

\subsection{Instruments of the Study}

This study adopted the qualitative approach to present the findings. As for data collection, only two instruments had been used in this study; a test and an interview session.

\subsection{Data Analysis}

The analyses of data require various methodologies that are connected to each other. As such, these strategies are adopted with the target to abridge the data that would be collected and to organize them in a way that can answers all the research questions.

\section{Literature Review}

8. In this study, several theoretical and empirical studies concerning idioms translation strategies from source language into target language had been looked by emphasizing on the difficulties, as well as the translation strategies for idioms from Arabic into English.

\subsection{Translation Strategies}

For instance, Krings (1986) characterized translation strategy as "a translator's conceivably cognizant plans for tackling solid translation issues in the structure of a solid translation task." Other than that Séguinot (1989) claimed that there are no less than three worldwide strategies utilized by translators, which are:

1. Translating without intrusion for whatever length of time conceivable

2. Adjusting surface blunders instantly

3. Leaving the checking for subjective or complex mistakes in the content to the correction department.

On top of that, Lörscher (1991) asserted translation strategy as "a conceivably cognizant method for taking care of an issue confronted in translating a text, or any segment of it." Hence, as depicted in this definition, awareness is deemed as significant in acknowledging the strategies that should guide fellow translators. As such, Cohen (1984)declared, "the component of cognizance tells if the strategies from these processes are vital or otherwise." Meanwhile, Jääskeläinen (1999) considered strategy as a progression of capabilities, or as an arrangement of steps or procedures that functions to support the acquisition, the storage, and the utilization of information. He also asserted that strategies are heuristic and adaptable in nature, and besides, their selection implies a decision impacted by revisions within the targets of the translators. Additionally, López Rodríguez (2009) believed that a translator ought to first realize what should constitute as strategies and what a translator ought to do in order to determine the correspondences in translating unacquainted lexicons and expressions. He further emphasized on the deconstruction of the sense of geographical names and politically stacked expressions with a specific end goal to portray the sensitivity of language, as well as the difficulties faced when studying in a multilingual setting.

\subsection{Problems in Translating Idioms}

Newmark (1988) has mentioned that in rendering idioms into idiomatic language, it is especially hard to match the meaning with its equivalent occurrence. He also stated that the principle issues a translator encounters are not syntactic, but rather lexical, i.e. words, collocations, and settled phrases or idioms. Moreover, Baker (2011) claimed that the major challenges that idiomatic and settled expressions discompose in translation are related to two main fields: the capacity to identify and to translate an idiom appropriately, as well as the complications in translating several aspects of meaning that an idiom or a fixed expression carries into the target language. Additionally, Mollanazar (2004) pointed out clearly that the initial step in rendering idioms is to identify them. Thus, the pitfall for translators is to decipher the idioms accurately. Besides, word-for-word translation for idioms is often nonsense or even, sometimes, interesting

Furthermore, according to López Rodríguez (2009) one glaring problem a translator faces in translating idioms is the lack of equivalence on the idiom level. All languages have idioms. However, it is not easy to find an equivalent in the target language that corresponds to the idiom in the source language in both form and meaning. This is because; idioms may contain a culture-bound aspect that poses a problem for a translator. Thus, Catford (1965: 49) contended that the meaning of idiomatic is not indistinguishable with the aggregate meaning of their constituents, hence making it difficult to translate idioms word-for-word in most cases. The idiom or the phrase is considered as the unit of translation. He further stated that idioms ought not to be considered as the main conceivable translation components on the level of combination of words. Simply put, such a unit can be "a free blend of words whose source language meaning is developed out of the meaning of its different components."

On top of that, Larson (1984) pointed out that translators who need to make a respectable idiomatic translation would frequently discover that figures of speech is particularly a challenging feat. A literal translation, for instance, the idiom 'blind as a bat' might sound truly strange in a language where the correlation between a blind person and a bat never exists as a figure of speech. Nevertheless, in Aguaruna, it would be more apt to express 'as blind as a fox', due to a legend that claims the sun obtained the fox's eyes and then returned to heaven taking along the fox's good eyes with him, and leaving the fox with sun sub-par eyes. Other than that, Baker (1992) asserted that translators need to consider the various factors embedded in translating idioms, for example, accessibility of an idiomatic expression with a comparable meaning in the target language, the noteworthiness of a particular lexical item that constitutes the idiom, i.e. 
whether they are employed elsewhere in the source language, as well as the suitability or impropriety of utilizing the idiomatic language in a certain register in the target language, style, register, and rhetorical effect. Besides, she believes that idioms and settled expressions, which contain cultural aspects, cannot be translated accurately. This is because; it is not the particular items an expression contains, which can make it untranslatable or problematic to translate. Therefore, Regmi et al. (2010) pointed out a smart notion by expressing that albeit all translation exercises there is an unavoidable loss of various idioms. Nonetheless, some idioms may be regained by adopting appropriate strategies.

\subsection{Previous Studies}

Due to the peculiar nature of idioms, their rendering can be, to some degree, problematic at times. Hence, idioms must be perceived, comprehended, and broken down before suitable translation strategies can be taken into consideration. Hence, translators must possess the capacity to spot idioms from a text because it is completely significant that a translator is able to perceive an idiom when one comes across one. Besides, the capacity to distinguish idioms is of huge importance, since their meaning ought to never be understood in a literal manner.

Likewise, Skorupa and Baranovskaja (2012) carried out a review that looked into the idiomatic terms in the conventional media and picked the best and the most apt equivalents for some terms in Lithuanian. Moreover, the paper elucidated the significance of phrases and idioms. The paper also introduced an overview of the English media informal terms, in comparison to their Lithuanian equivalents. The examined terms were characterized into four gatherings as dictated by their meaning. The main difficulty confronted was that some English idiomatic media terms needed Lithuanian translation counterparts, in this manner, whatever point conceivable, translation suggestions were offered. Therefore, in order to effectively comprehend and decipher the approaching data, certain knowledge of lexical elements, linguistic knowledge, and recognition of grammatical structures have been strongly required to avoid conceivable troubles.

On a different note, Mahmoud (2013) explored the translation of some Arabic and English idioms, besides concentrating on the issues confronted by students and translators. Some Arabic and English idioms were chosen with their translations. Besides, he elaborated the contrasts between literal translation and translating the source language idiom with the corresponding target language idiom. As a result, the general outcomes demonstrated that idioms could never be deciphered literally; equivalence, context, and semantic relativism ought to be considered when translating idioms. Hence, it has been strongly suggested that translators, as well as learners, have to be completely aware of some translation methods, as well as the context of the discourse one is dealing with. Meanwhile, Migdadi (1994) found that with regard to idioms, students utilized several strategies, such as approximation, literal translation, and avoidance for translation. These strategies were brought on by absence of perception and regularly brought about lexical errors. Other than that, Wahhab (2002) discovered that the primary reasons for students to confront challenges when dealing with idioms are their fixed word orders, non-literal meanings, as well as the special word grouping of some idioms. Moreover, he added that the absence of cultural knowledge on the part of students, inclusive of learning the language in a non-native speaker atmosphere, emerges as some factors that contribute to certain issues. Similarly, Baker (1992) pointed out that the primary challenges in relation to idioms in translation can be classified as follows:

1. Absence of an equal expression in the target language

\section{A target language equivalent that has an alternate setting of utilization}

3. Utilizing the source language idiom in its idiomatic and its exacting implications for the purpose of producing significance.

4. Recurrence of idioms use in written texts varies from one language to another.

On top of that, Ghazala (2003) explained that direct idioms are deciphered straightforwardly, yet literally have figurative implications, for instance, stab in the back الظهر في يطعنة, while indirect idioms are deciphered indirectly and therefore, their implications must be induced from the context. On the other hand, Al-Hamdalla (1998) clarified that translators ought to attempt to locate an equivalent form for an idiom in the Arabic language, or else they ought to give an identical clarification. On the other hand, Ayoub (1994) claimed that the issues that arise from translating idioms can be grouped into cultural and linguistic problems. This is because; some issues might be ascribed to the expansive linguistic and cultural gaps between Arabic and English since the two languages belong to two language families and two cultures that are completely unique.

Meanwhile, on a comparable note, Bataineh et al. (1996) examined the issues that cropped up from translating English idioms into Arabic by Jordanian Translation students. She, likewise, explored the reasons of these issues, the types of idioms that are challenging, as well as the strategies utilized as part of deciphering idioms. As a result, it was discovered that any oversight or error of the idiom led to loss or misrepresentation of the meaning or coherence. Additionally, she clarified that the subjects faced problems with idioms basically because they were culture-specific. Sometimes, the students failed to recognize them as idioms, which led to literal translation. Finally, she found that her subjects essentially adhered to the translation strategies suggested by Baker (1992).

Similarly, Badavi (2008) conducted a study on a number of imminent English Foreign Language teachers at the University of Tabouk. He examined their capacity to decipher culture-specific expressions, as well as their knowledge on translation strategies. The findings pointed out that their translation capacity was poor, likewise their familiarity of translation strategies. He also found that they regularly turned to literal translation. 
Meanwhile, Aldahesh (2008) investigated several issues concerning Middle Easterner expert translators and students when translating idioms in English into Arabic, and proposed several suggestions for proficient translators, pedagogues, and lexicographers. In his study, translation tests were conducted to recognize sorts of mistakes and translational pitfalls. The study further revealed multiple issues when dealing with idioms of English phrasal verbs. The most glaring issue is the inability to accomplish useful practical counterparts of such verbs. Moreover, mistranslating literal translation, reducing idioms to sense and rupturing of the Arabic language system, along with blunders, such as wrong Arabic, shift of register, collocation, incorrect delivery of speech acts, usage of Arabic colloquial, regional dialects, and usage of paraphrasing, had been listed as the major reasons behind the failure of delivering suitable translation in target language.

On top of that, López Rodríguez (2009) examined some issues faced by third year License Master students from the English Department at the University of Mentouri in translating idioms and proverbs from Arabic into English, with the aim to improvise students' results. The researcher carried out a test that contained 20 Arabic and English idioms and proverbs for 3rd year LMD students to be rendered in both directions: Arabic into English, and vice versa. The findings obtained demonstrated that the translation carried out by the participants had been absolutely insufficient, as well as the fact that the cultural awareness that they possessed failed in empowering them to construe the intended meaning of the fixed expressions in an effective manner or their potential to decipher them accurately. Subsequently, a majority of the students depended on literal translation or they were just ignored without interpretation. In fact, some of them turned to elucidation, which was inaccurate by approximately $73 \%$ of the entire rate of these cases.

In another study, López Rodríguez (2009) analyzed the sort of troubles faced by students pursuing Master's degree while translating idioms, thus suggested some solutions and distinguished strategies that may overcome those challenges. Hence, a test that comprised of twelve English idioms and ten Arabic ones was given to the participants for translation. The outcomes of the study listed some potential issues during the process of translating idioms from English into Arabic and vice versa. Moreover, the discovery demonstrated that the students did not utilize the correct strategies that may help with suitable guesses. Furthermore, for both Arabic and English translations, they adhered to word-forword translation, cultural substitution, and paraphrasing strategies, but in an unsuitable way. They also affirmed their hypotheses and showed that except for word-for-word translation, the utilization of other translation strategies by the students was constrained. Therefore, the students frequently succeeded in translating straightforward idioms and semi-transparent idioms, but with opaque and semi-opaque categories, they were completely befuddled in the fact that idioms have to be taken as a solitary unit to generate meaningful translations.

In addition, Wełnowska (2010) investigated the main problems and difficulties faced by Polish learners of English, as well as the extent to which the meaning of the idioms is retained, distorted or lost, and the reasons for such misinterpretation. Moreover, several solutions and procedures were suggested to keep losses at a minimum level, besides becoming more creative in translation. This study was illustrated with examples of translations (from Source Language, 30 being English, to Target Language, which is Polish), that were derived from the outcomes of a survey conducted on four groups of students from the Adam Mickiewicz University. The findings showed that the majority of the participants did comprehend the English idioms, but displayed the tendency to translate their meaning, instead of using their idiomatic Polish equivalents. Moreover, machine translators cannot be trusted when translating idioms, as in most cases, the idiomatic phrases are translated literally. Finally, the study concluded that the best method for translation was the one initiated by the human translator who was informed to use Polish idioms. Otherwise, the human translator with the access to aids, such as dictionaries, would have been the most successful.

On the other hand, González Davies (2004) listed the difficulties faced by students in translating idioms and fixed expressions:

\section{No correspondence in the target language}

2. A comparable equivalent in the target language with a dissimilar context of use

3. An idiom used in the source text both in its literal and idiomatic sense at the same time

4. Variance between convention, context, and frequency of usage in both source and target languages

Hence, from the review of several prior studies, it has been observed that most a studies did highlight the difficulties and the strategies of translating idiomatic expressions from source language into target language, as well as the students' experiences while deciphering such texts. In addition, the dominant aspect of these studies is the application of translation tests as an instrument to gather, as well as to analyze data. In this present study, the researcher has benefited from these tools and added the interview instrument to attain results that are more reliable.

\section{Data Analysis}

The qualitative data have projected various helpful features in this study. First, they provided the actual information that allowed the researchers to better comprehend the problem associated to translating idioms from Arabic language to English language as a phenomenon. Second, they reflected the results obtained from other means of data collection methods. Third, they consisted of some inseparable abundance and holism, which means mental and social factors, with great potential for intricacy. Lastly, they are usually gathered over a long time, allowing for longitudinal analyses of social and historical processes. 
8.1 Responses to the Test

A test was given to the respondents. For this study, the test was employed as data collection methods. The test was carried out to determine more about the problem associated to translating idioms from Arabic language to English language as a phenomenon.

\subsection{1 القناعة كنز لا يفنى (Content is an everlasting treasure)}

Figure 8.1.1 shows the frequency count of responses to the statement: يفنَ لا كنز القناعة (Content is an everlasting

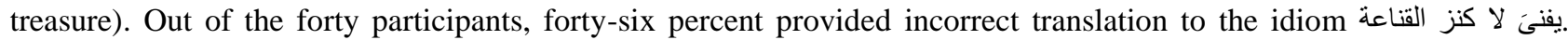
Besides, as depicted in the figure, fourteen percent gave the correct translation to the idiom يفنَ لا كنز القناعة . Meanwhile, thirty-four participants employed transliteration to render the idiom يفنَ لا كنز القناعة . However, twelve percent of the participants gave incomplete meaning, whereas four percent left the answer blank. Figure 4.1 describes the results obtained from the translation test carried out among the forty participants.

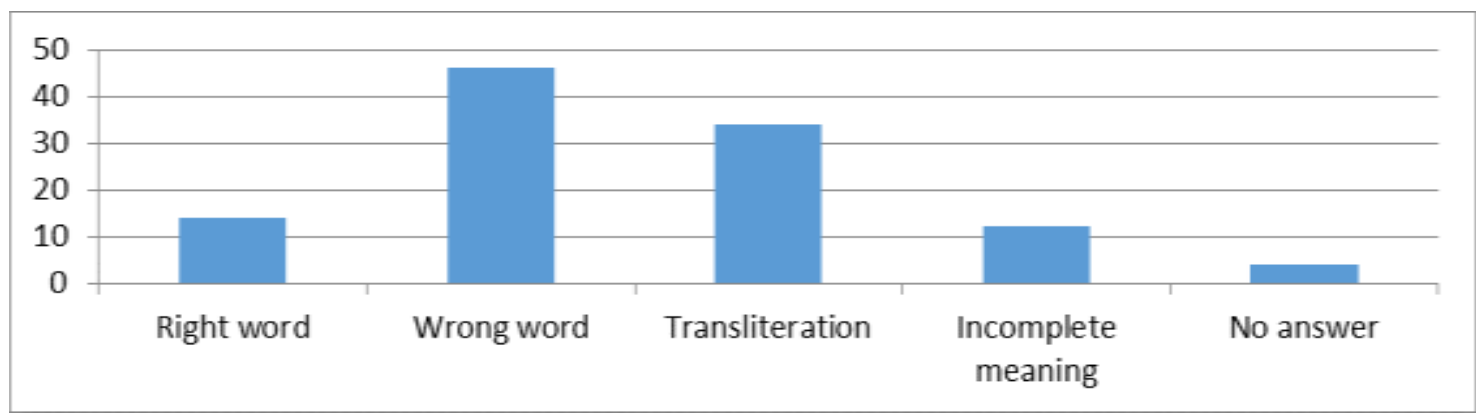

Figure 8.1.1

\subsection{2 اللي استحو اماتوا (Those who fear are dead)}

Figure 8.1.2 shows the frequency count of responses to the statement:ماتو ا استحوا اللي (Those who fear are dead). Out of the forty participants, sixty-three percent translated wrongly for the idiom ماتوا استحو ا اللي. Moreover, the figure depicts that fifteen-percent had managed to provide the correct translation for the idiom ماتو ا استحو ا اللي. Other than that, twentyone participants used transliteration to render the idioms ماتو استحو ا اللي. However, one percent of the participants gave incomplete meaning in rendering the idioms ماتوا استحوا اللي. Finally, one percent of the participants rendered the idiom مانوا استحوا اللي Figure 10.3 showcases all the results obtained from the translation test carried out to the forty participants.

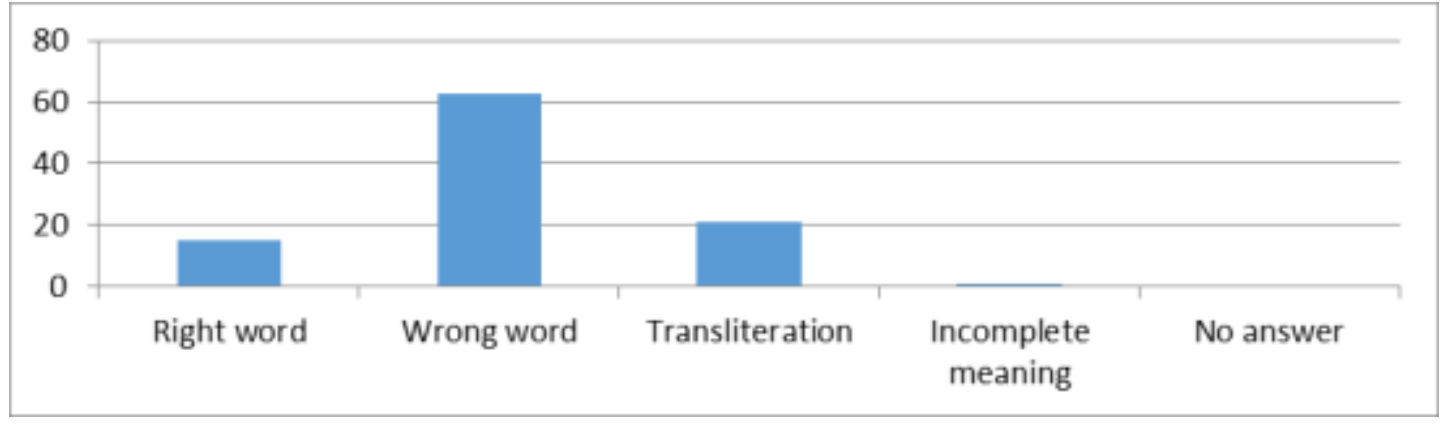

Figure 8.1.2

\subsection{3 خالف تُعْرَفْت (Dissent and you will be known)}

Figure 8.1.3 presents the frequency count of responses for the statement: تُعْرَتَ خالف (Dissent and you will be known). Out of the forty participants, eighty-three percent wrongly translated the idiom تُعْرَفْ خالف. Besides, as observed from the figure, five-percent of the participants provided the correct translation for the idiom خُرَف participants used transliteration to render the idiom تُعْرَتَ خالف. However, seven percent gave incomplete meaning, while none left the answer blank for the idiom تُعْرَفْ خالف. Figure 10.4 displays the results obtained from the translation test carried out among the forty participants. 


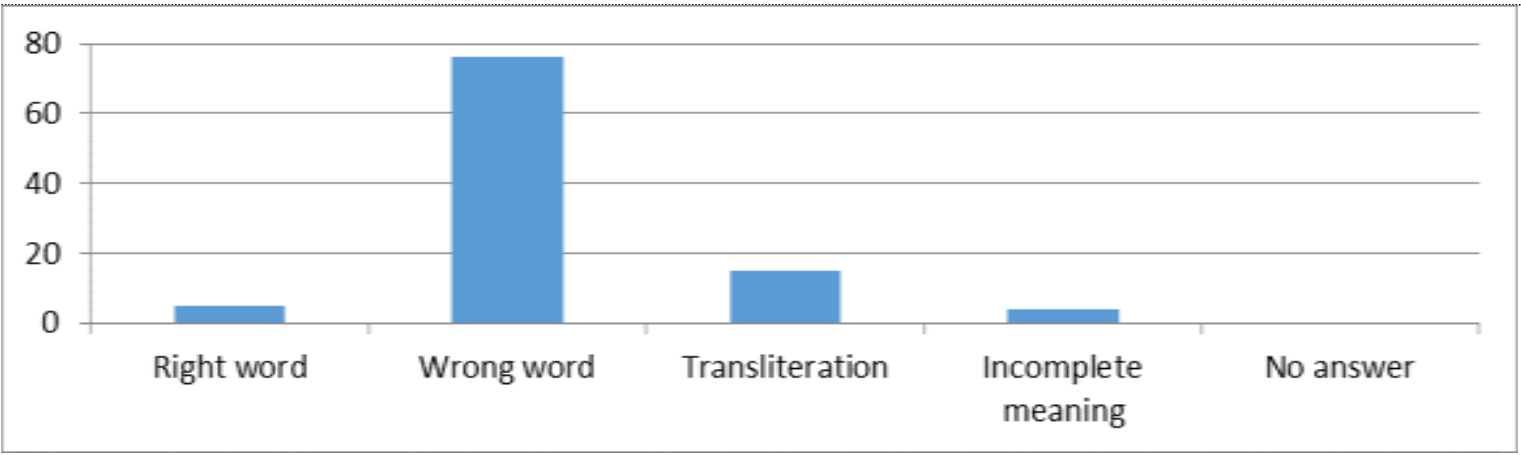

Figure 8.1.3

\subsection{4 خالف هو الك ترشد(Oppose your affection to find rationality)}

Figure 8.1.4 exhibits the frequency count of responses to the statement: ترشد هو اك خالف (Oppose your affection to find rationality). As a result, forty-three percent of the participants translated wrongly, while forty-eight percent correctly translated the idiom ترشد هو اك خالف. Other than that, seven participants used transliteration to render the idiom وَ الثُّ الخير. However, only one percent of the participants did not complete the answer, and another one percent failed to provide answer. Figure 10.2 shows the results of the translation test conducted among the forty participants.

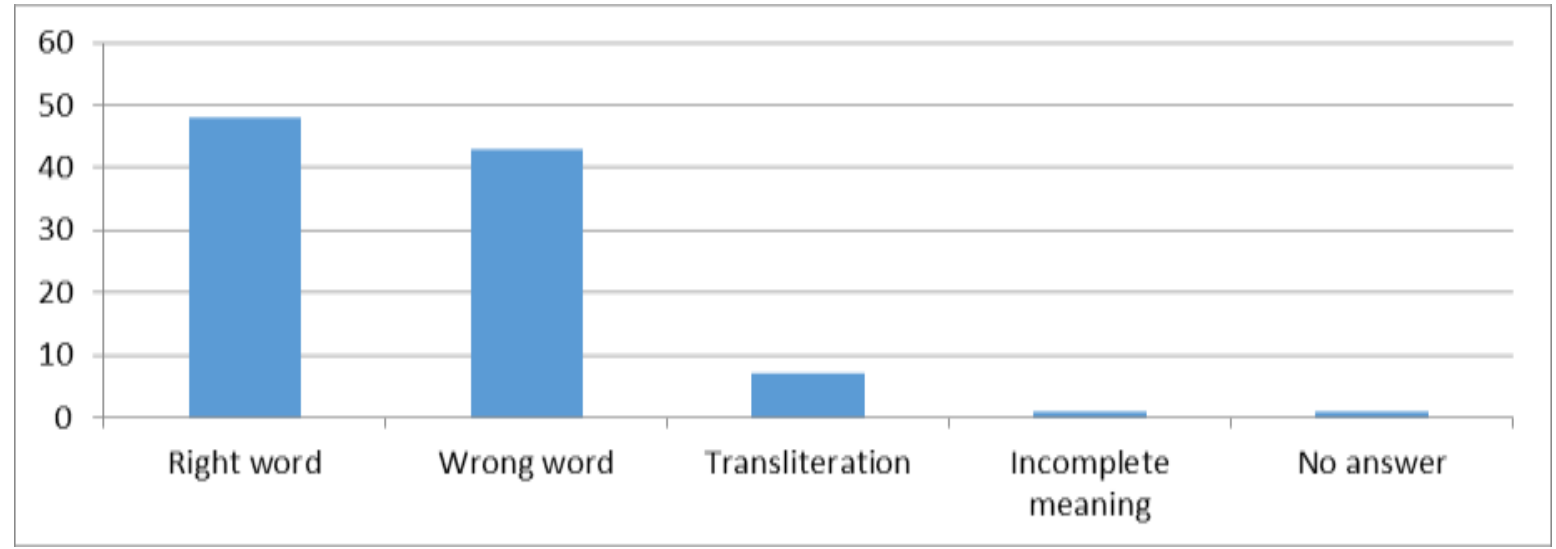

Figure 8.1.4

ضربني وبكى وسبقني و اشتكى (He beat me and cried, and went before me to complain)

Figure 8.1.5 demonstrates the frequency count of responses to the statement: واشتكى وسبقني وبكى ضربني (He beat me and cried, and went before me to complain). In fact, as many as sixty-eight percent of the participants wrongly translated the idiom و اشتكى وسبقني وبكى ضربني. Besides, five percent provided the correct translation, while fifteen of them used transliteration to render the idiom واشتكى وسبقني وبكى ضربني. However, eight percent of the participants gave incomplete answer, whereas four percent did not answer for the idiom واشتكى وسبقني وبكى ضربني. Figure 10.5 shows the results retrieved from the translation test carried among the forty participants.

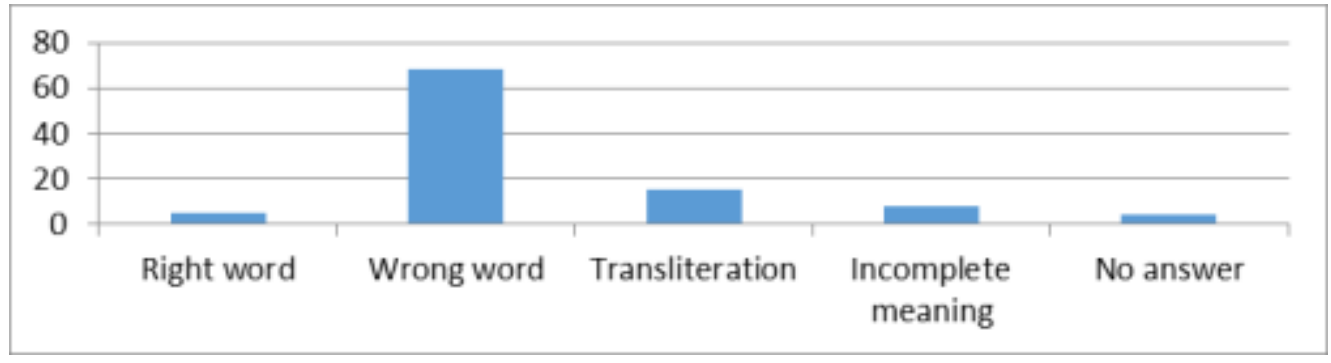

Figure 8.1.5

عصفور في اليد خير من عشرة على الثجرة 8.1.6 (a bird in the hand is worth two in the bush)

Figure 8.1.6 shows the frequency count of responses to the statement: الثجرة على عشرة من خير اليد في عصفور (a bird in the hand is worth two in the bush). Out of the forty participants, fifty-four percent translated wrongly, while only four percent had given the correct translation for the idiom الََْنْسُوُ الْحَدِيُ transliteration to render the idiom الشجرة على عشرة من خير اليد في عصفور. However, fifteen percent of participants gave incomplete answer, whereas five percent did not answer the idiom الثجرة في على عشرة من خير اليد في عصفور. Figure 10.6 describes all the results obtained from the translation test conducted among forty participants. 


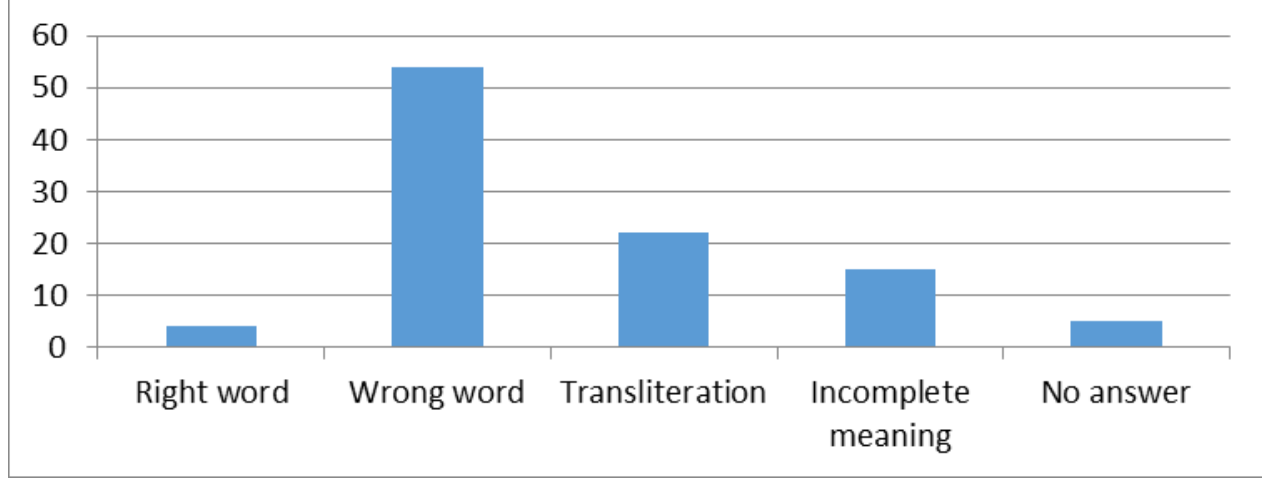

Figure 8.1.6

\subsection{7 أعط الخبز لخبازهولو أكل نصفه (Give the bread dough to the baker even if he eats half of it)}

Figure 8.1.7 presents the frequency count of responses to the statement: نصفه أكل ولو لخبازه الخبز أعط (Give the bread dough to the baker even if he eats half of it). Out of the forty participants, a whopping eighty-nine percent translated wrongly, while only a mere eight percent correctly translated the idiom نصفه أكل ولو لخبازه الخبز أعط. Moreover, only two of them used transliteration to render the idiom نصفه أكل ولو لخبازه الخبز أعط ولنو the answer blank for the idiom نصفه أكل ولو لخبازه الخبز أعط العط 10.7 shows the results from the translation test carried out among forty participants.

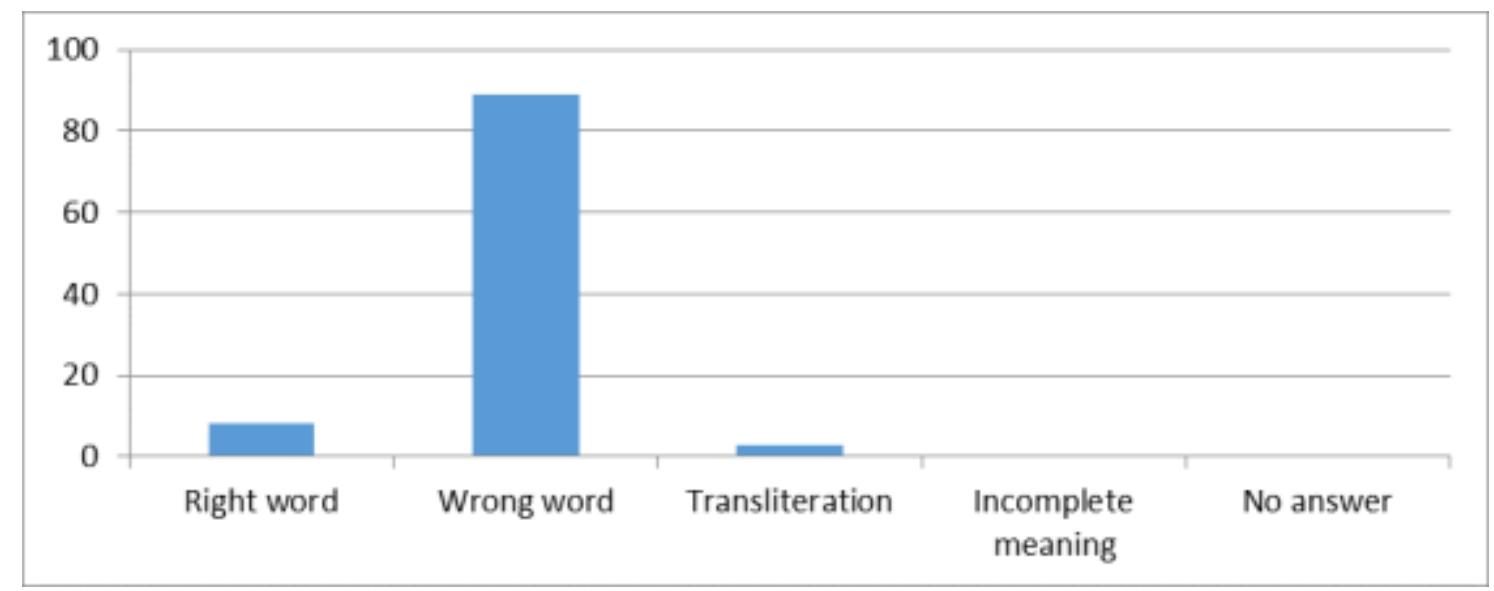

Figure 8.1.7

8.1.8 في العجلة الندامة و في التاني السلامة 8.8 (In haste there is regret and in taking time there is peace/safety)

Figure 8.1.8 shows the frequency count of responses to the statement:السلامة الثاني في و الندامة العجلة في (In haste there is regret and in taking time there is peace/safety). As a result, a high ninety-two percent of the participants gave wrong

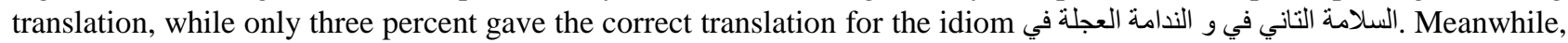
four participants used transliteration to render the idiom السلامة التاني في و الندامة العجلة في فowever, only one percent answered partially, while none left the answer empty for the idiom السلامة التاني في و الندامة العجلة في في فئلة 10.8 describes the results obtained from the translation test conducted to the forty participants.

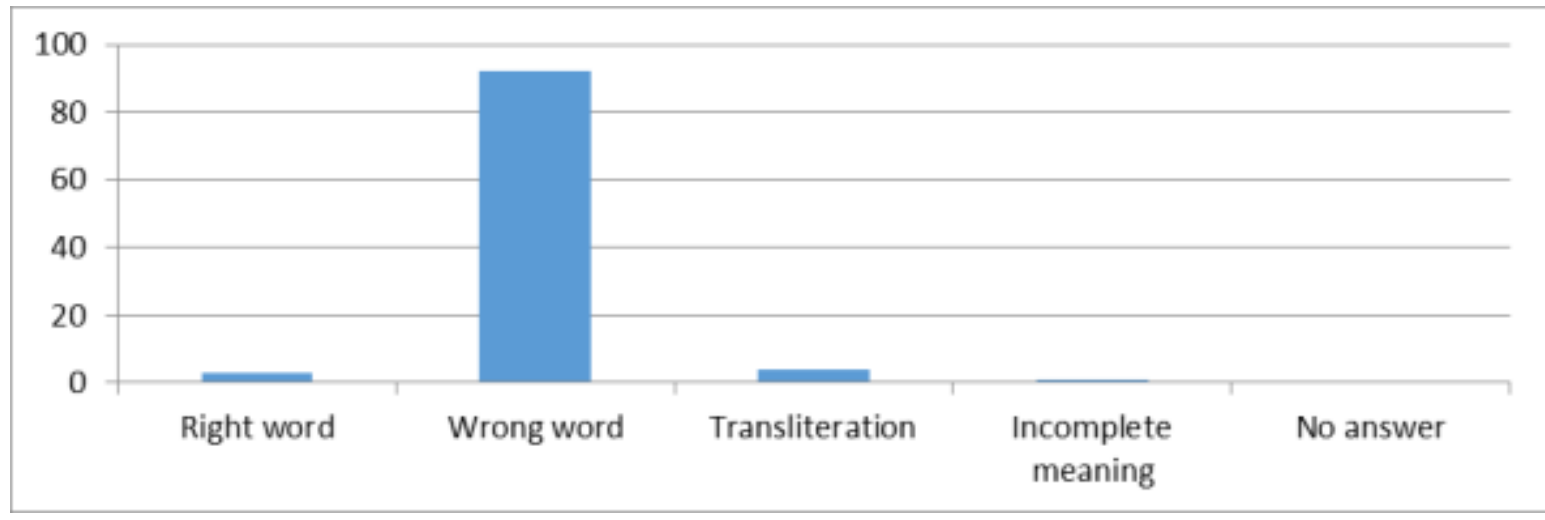

Figure 8.1.8

8.1. أن نأتي متأخر ا أفضل من أن لا تأتي Better late than never)

Figure 8.1.9 shows the frequency count of responses to the statement: نأتي لا أن من أفضل منأخر انتي أني أن (Better late than never). Of the 35 participants, seventy-two percent gave the wrong translation, while sixteen percent gave the right 
translation for the idiom تأتي لا أن من أفضل متأخر ا تأتي أن Besides, nine participants used transliteration to render the idioms شَدِيدُ عَذَابُ . In addition, two percent of the gaves partial answer, whereas only one percent of the participants did not answer. Figure 10.9 describes the results from the translation test among the forty participants.

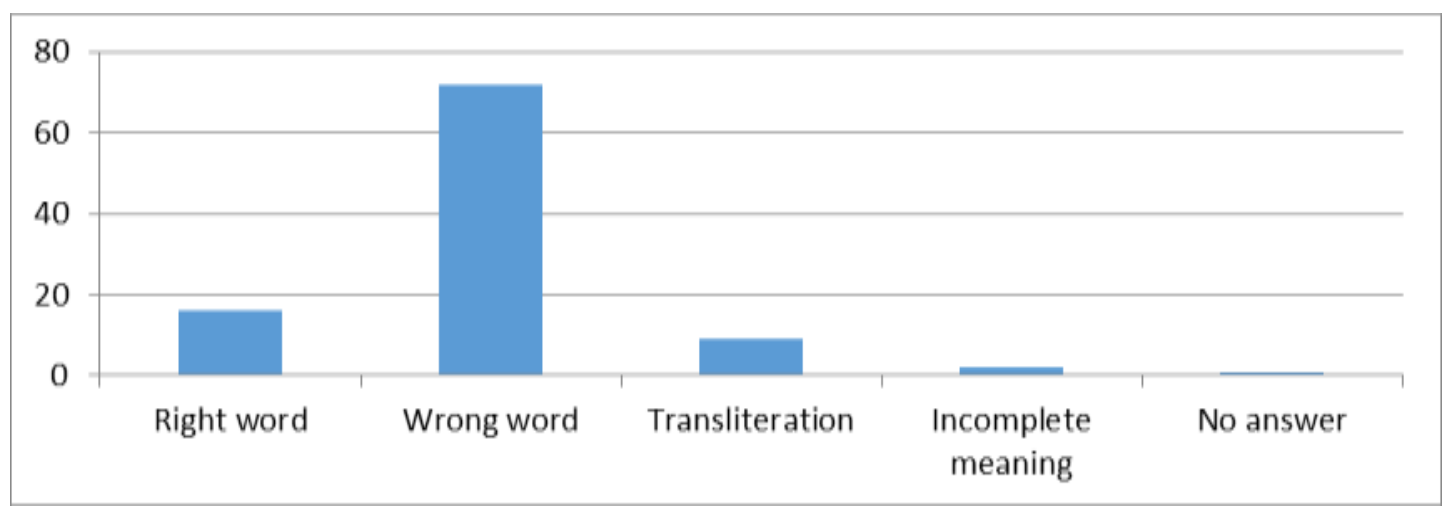

Figure 8.1.9

8.1 .10 الطيور على أشكالها تقع)(Birds with same feather flock together)

Figure 8.1.10 shows the frequency count of responses to the statement: تقع أشكالها على الطيور (Birds with same feather flock together). Out of the forty participants, eighty-five percent gave wrong translation, whereas eight percent gave the right translation for the idiom تقع أشكالها على الطيور. Besides, four of them used transliteration to render the idioms الطيور . However, two percent of the participants gave incomplete meaning, while one percent did not answer for the idiom تقع أنكالها على الطيور. Figure 10.10 shows the results from the translation test to the forty participants.

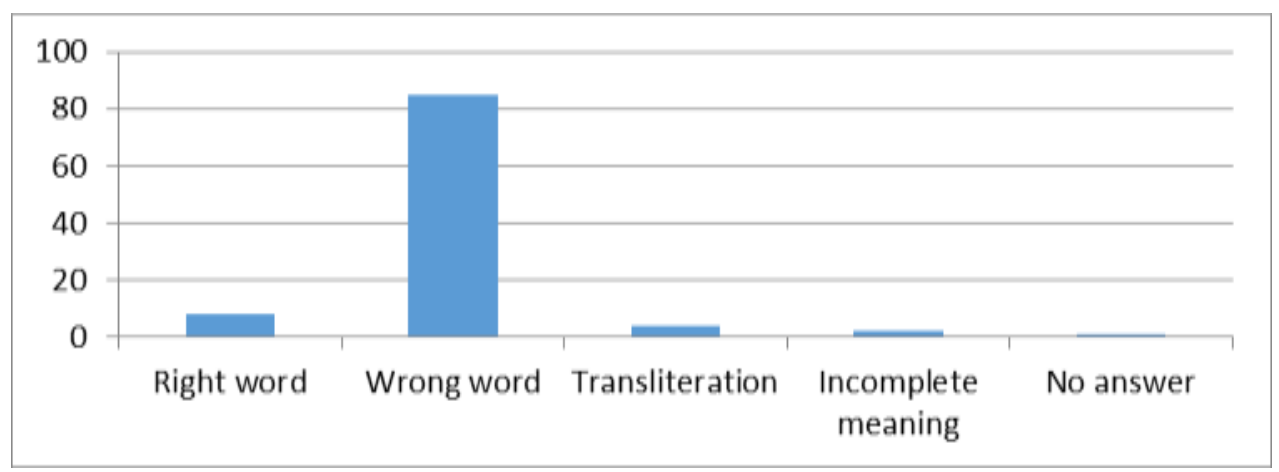

Figure 8.1.10

\subsection{Responses to the Interview Questions}

The researcher also conducted personal interviews with the respondents, as a means of data collection method. The interview was carried out to further investigate the issues that revolve around the process of translating idioms from Arabic into English. The answers offered by the participants are summarized as follows:

1. Lack of knowledge concerning the source language idiomatic expressions emerged as the main challenge for the students

2. Several students were ignorant of the strategies used in the process of translating idiomatic expressions

3. The cultural variations between the Arabic language and the English language surfaced as a factor that caused glitches in translating idiomatic expressions

4. Idioms may have a comparable equivalent in the target language, but with varied meaning

5. The majority of the students ignored how to transact with idiomatic expressions; they translate each word in the expression rather than dealing with the expression as a whole unit

6. Some idiomatic expressions do not have a direct equivalent in the target language.

7. Poor linguistic and pragmatic levels among the students emerged as some of the main causes of facing difficulty translating idiomatic expressions.

8. The items used in the idiomatic expression are peculiar to Arabic language culture

9. Some of the students dealt with idiomatic texts as normal texts.

10. The students exhibited the tendency to give additional information that is not applicable in idiomatic expression translation.

11. Some of the Arabic idiomatic expressions are commonly used in various Arabic dialects rather than the standard Arabic, which dismisses standard equivalent. 
12. The linguistic structure of the idiomatic expressions is dissimilar from that of the normal language structure.

\section{Discussion}

The data analysis results obtained from the test and interview revealed that translation of idioms are indeed problematic as far as the current study is concerned. In fact, most of the translation problems faced by the students determined in this study can be grouped under several factors, such as a cultural variance between Arabic language and English language, misuse of the literal translation approach, and lack of one-to-one equivalence between Arabic language and English language in terms of idiomatic expressions. Moreover, as the students were unfamiliar with the omission strategy for translation, it had been difficult for them to decide when or where to delete or to add on concepts in the target language. As such, the results highlighted the glitches faced when translating idioms. The students failed in providing suitable and accurate meaning of idiomatic expressions from the Arabic language into the target language, which affected the degree of translation quality, hence failing to translate them successfully. In addition, translation is not an easy activity, which can be simply carried out. Therefore, translators are often faced with confusing problems and complications while translating, which demand certain capacities and competences on their part. Moreover, it is essential for translators to be more conscious and well-accustomed with the cultural environment of the target language. Hence, knowledge of the second language culture is considered as an indispensable requirement among translators for successful translation of specific cultural concepts.

\subsection{The Test}

The idiomatic expressions are an indispensable part of the culture and have a huge impact upon our daily lives. Therefore, translating daily conversations, which are full of idiomatic expressions, into English requires knowledge of the cultural nuances of Arabic idiomatic expressions, as well as awareness of the translation process. As such, the findings obtained from the present study exhibit that idiomatic expressions represent actual obstacles for students for translation from Arabic language into English language. Furthermore, the data analysis of the test that had been conducted in this study revealed that the challenges encountered by the students while translating idiomatic expressions from Arabic into English stem from lack of awareness on cultural variances between Arabic and English languages. Besides, a majority of the students displayed the tendency to apply the cultural features embedded in the source language to the target language, thus resulting in changing the cultural perspectives of the target language where both educated learners and non-educated learners would fail in comprehending the proposed meaning of such an expression. Besides, it is inadequate for translators to be bilingual, but better if bicultural. Moreover, translators ought to have deeprooted awareness of both source and target language cultures that should enable them to acknowledge the sociocultural patterns of these cultures, as supported by Al-Sohbani and Muthanna (2013).Moreover, the results obtained from the test conducted indicate that the selection of a fitting translation strategy in translating idiomatic expressions is indeed a challenge for the students. Besides, the ideal utilization of the strategies in translating idiomatic expressions by the learners and the literal translation revealed the lack of understanding among students towards idiomatic expressions. In fact, some translated literally without providing any clarification or footnote, which resulted in babble expressions. Furthermore, a number of them utilized the Google translation service or guessed the meaning based on the components in the expressions, which is in agreement with the results retrieved by López Rodríguez (2009) .

Additionally, the test data analysis indicated that some learners failed to distinguish between the categories of idioms, metaphors, similes and binomials, as well as proverbs, without knowing how to manage each of them. In addition, the study pointed out the inability of the students in identifying a target language identical to the idiom due to their lack of knowledge on semantic characteristics and pragmatics of idiomatic expressions, besides being unfamiliar with the hidden meaning, whereby the idiom may have an equivalent notion in the target language. Besides, the failure to discover a target language equivalent constitutes as a noteworthy challenge for these students as they portray a lack in aesthetic perspective. In fact, this outcome concurs with Taber (1982). Furthermore, the study demonstrates that a vast majority of students faced the challenge of grasping the internal meaning of idiomatic expressions that they had been unaware. The meaning of idiomatic expressions does not derive from the entirety of its constituents, but rather, it must be dealt with in general unit. Hence, idiomatic expressions differ greatly from the same normal expressions, which is in agreement with that of (Langlotz, 2006) Furthermore, the study revealed that students may be unaware of an idiom that has a similar corresponding in the target language, but with various meaning, in which the translator may end up translating wrongly, hence is in agreement with the notion asserted by Baker (1992).

\subsection{The Interviews}

The interview was conducted to determine the complications and the difficulties faced by the students in the translation process of idioms from Arabic language to English language. The results of the interview exemplified that the students had no clue dealing with idiomatic expressions that may be culturally inappropriate or embarrassing. As such, a translation strategy of deletion or omission of certain terms was adopted as the final choice, which had been used only when the terms had been either too difficult to translate or there are similar words in the second language. This strategy, nonetheless, might slightly distort the real meaning of a concept that is being translated. Moreover, the translation theory does not offer any specific a set of rules that one can adhere to, especially to assure that the translator is indeed providing an acceptable translation. This very fact was also highlighted by who claimed that translation theory helps a translator acknowledge several factors involved in the translation procedure, besides providing ways and strategies to make apt choices and selections in the translation process. Meanwhile, the results of the interview questions illustrated that the learners were unaware of the significance of cultural aspect while translating idioms from Arabic language into English language. When an idiomatic expression has no direct equivalent in English language, the answers given by the 
participants hinted that they were clueless about translating idiomatic expression. Besides, they preferred simple words, which could be translated via word-to-word translation, and it appeared that they did not have any experience in translating idiomatic expressions. Besides, these findings are similar to those discovered by Mahmoud (2013). On top of that, the outcome of this interview session showed that the participants did struggle with concepts absent in the English language. When the direct equivalents do not exist in the second language, there is space for translation by using the transliteration method. However, transliteration should not be used, unless the translation is difficult Saleh et al. (2011). Besides, the interview session also revealed that the participants were unsure of the equivalent word in second language. In fact, translation via paraphrasing is another way to deal with challenging items in translation. Nonetheless, when the translator employed the paraphrasing strategy, it was realized that the concept translated had a variety of equivalent forms in the target language. Hence, the main benefit of translating using the paraphrasing method is gained when seeking for a high level of exactness in determining the meaning of a cultural concept .

\section{Conclusion}

The study revealed that the students' ability to translate idioms from Arabic language into English language is limited. Besides, one may conclude that the variety in strategies adopted by students is a reflection of the variance in students' linguistic and pragmatic competence, as well as the degree of their familiarity with these idioms. Moreover, it seemed that the students had difficulty in determining the suitable equivalent term in English, which is vivid as they failed in using the correct or acceptable equivalent when translating idiomatic expressions. This may be attributed to several factors, for instance, they are not exposed to the culture of the target language, they are unfamiliar with the target language cultural expressions, as well as the gap that exist between the two cultures. Moreover, the results obtained from this study have answered the first research question, i.e., "what are the obstacles of translation strategy encountered by the students in translating idioms from Arabic language into English language?' Hence, some obstacles of translation strategy when translating idioms from the Arabic language to the English language had been examined and identified, which are due to the absence of strategy knowledge among the students. In fact, similar findings have been reported by who asserted that the learners' inadequate awareness about the translation strategy could contribute to the usage of improper translation strategies. Next, the present study has also answered the second research question, i.e., 'How do the students deal with various translation strategies in translating idioms from Arabic language into English language?' Furthermore, it is worth emphasizing that most idiomatic expressions represent implicit meaning, which is hidden by the linguistic structures produced by students. These words are conventionally, culturally, and pragmatically associated with the Arabic language. In addition, the difficulty of the translation process that involves idiomatic expressions that cannot be avoided because cultural concepts of the source language are embedded with connotative meaning. Thus, readers of the target language may not be able to grasp the real meaning of the words, in which they may only understand some linguistic elements of certain words. In this regard, the translator should use the compensation strategy to make the representation look clearer Arcos-Garcia (1996). Hence, in order to meet the objectives of the present study; the researcher has highlighted several challenges and obstacles encountered by these students when translating idioms from the Arabic language to the English language.

\section{References}

Adelnia, A., and Dastjerdi, H. V. (2011). Translation of idioms: a hard task for the translator. Theory and Practice in Language Studies. 1(7), 879-883.

Al-Hamdalla, R. (1998). Problems and approaches to translation with special reference to Arabic. Journal of King Saud University.

Al-Sohbani, Y., and Muthanna, A. (2013). Challanges of Arabic-English Translation: The Need for Re-systematic Curriculum and Methodology Reforms in Yemen. Academic Research International. 4(4).

Aldahesh, A. (2008). Translating idiomatic English phrasal verbs into Arabic. College of Arts: University of Western Sydney.

Arcos-Garcia, F. (1996). On translating figurative language from English into Spanish: A perceptual problem. Babel. 42(3), 158-165.

Ayoub, Y. (1994). Some linguistic and cultural problems in translating idiomatic expressions from Arabic into English and vice versa. Irbid: Yarmouk University. An Unpublished MA Thesis.

Badavi, M. (2008). Investigating EFL Prospective Teacher's Ability to Translate Culture-Bound Expressions. Online Submission.

Baker, M. (1992 ). In other words: a coursebook on translation. Routledge.

Baker, M. (2011). In other words: A coursebook on translation. Routledge.

Bataineh, R. F., Wardat, M., and Bader, Y. (1996). The ability of Jordanian graduate students to translate English idiomaticexpressions into Arabic.

Catford, J. C. (1965). A Linguistic Theory of Translation: an Essay on Applied Linguistics. London: Oxford University Press.

Cohen, A. D. (1984). On taking language tests: What the students report. Language testing. 1(1), 70-81. 
Cowie, A. P., and Mackin, R. (1975). Oxford Dictionary of Current Idiomatic English Volume 1,(entitledOxford Dictionary of Phrasal Verbs' 1993). Oxford, Oxford University Press.

Ghazala, H. (2003). Idiomaticity between evasion and invasion in translation: Stylistic, aesthetic and connotative considerations. Babel. 49(3), 203-228.

González Davies, M. (2004). Multiple voices in the translation classroom: Activities, tasks and projects. John Benjamins Publishing.

Gottlieb, H. (1997). Quality revisited: The rendering of English idioms in Danish television subtitles vs. printed translations. BENJAMINS TRANSLATION LIBRARY. 26309-338.

Hawkins, R. P., Pingree, S., and Adler, I. (1987). Searching for cognitive processes in the cultivation effect adult and adolescent samples in the United States and Australia. Human Communication Research. 13(4), 553-557.

Jääskeläinen, R. (1999). Tapping the process: An explorative study of the cognitive and affective factors involved in translating. Joensuun yliopisto.

Krings, H. P. (1986). Translation problems and translation strategies of advanced German learners of French (L2). Interlingual and intercultural communication. 263-276.

Langlotz, A. (2006). Idiomatic creativity: a cognitive-linguistic model of idiom-representation and idiom-variation in English. John Benjamins Publishing.

Larson, M. L. (1984). Meaning-based translation: A guide to cross-language equivalence. University press of America Lanham, MD.

López Rodríguez, C. L., José Antonio Prieto Velasco and Maribel Tercedor Sánchez (2009). "Sharing Environmental Information through Multilingual Terminological and Multimedia Resources: The Role of Accessibility in Increasing Public Awareness Towards Sustainable Growth.” Jiří Hřebíček Et Al. (Eds) . Towards Eenvironment. Opportunities of Seis and Sise: Integrating Environmental Knowledge in Europe. Prague: Masaryk University, . (2009). Prague: Masaryk University.

Lörscher, W. (1991). Translation performance, translation process, and translation strategies: A psycholinguistic investigation. G. Narr.

Mahmoud, M. M. A. (2013). Investigating Some Lexical Problems in English- Arabic Translation

Confronted by Undergraduate Students and Proposing Solutions for them. International Journal of Scientific \& Engineering Research. 4.

Migdadi, F. (1994). Lexical choice: Investigating lexical learning strategies of Arabic speaking

learners of English Master. Yarmouk

Mollanazar, H. (2004). Translation Movement. Translation Studies Quarterly. 2(6).

Newmark, P. (1988 ). A textbook of translation. New York, USA: Prentice Hall.

Paluszkiewicz-Misiaczek, M. (2005). Strategies and Methods in Dealing with Culture Specific Expressions on the Basis of Polish-English Translations of Certain Administrative and Institutional Terms. Theory and practice in English studies: proceedings from the Eighth Conference of English, American and Canadian studies (linguistics, methodology and translation), Masaryk University.

Regmi, K., Naidoo, J., and Pilkington, P. (2010). Understanding the processes of translation and transliteration in qualitative research. International Journal of Qualitative Methods. 9(1), 16-26.

Saleh, K. H. A., El-Isa, S., Sameer, E., An, O., and Hirzallah, R. (2011 ). Translating Restaurants' Menus From English Into Arabic: Problems And Strategies.

Séguinot, C. (1989). Understanding why translators make mistakes. TTR: traduction, terminologie, rédaction. 2(2), 7381.

Skorupa, P., and Baranovskaja, I. (2012). English idiomatic words and their equivalents in Lithuanian as terms in traditional media. Philology and Educology Journal. 20(2).

Speake, J. (2008). Oxford dictionary of proverbs Oxford University: Oxford: .

Taber, N. A. (1982). The theory and practice of translation. Nertherlands: Leden. E. J.

Wahhab, S. I. A. (2002). Understanding and usage of english idioms: a problem encountered by jordanian efl learners. Yarmouk University.

Wełnowska, J. (2010). English idioms and aspects of their translation into Polish byPolish learners of English Adam Mickiewicz University. 